\title{
Do Periodically Collapsing Bubbles In Latin American And Asian Emerging Markets Really Exist?
}

Eric Girard, Siena College

Amit Sinha, Indiana State University

Megan Y. Sun, University of Wisconsin-River Falls

\begin{abstract}
As asset pricing, especially in emerging markets has been of continued interest in finance, this paper contributes by investigating the presence of periodically collapsing bubbles in seven Asian and seven Latin American emerging markets. Although a number of studies, using different approaches have studied presence of bubbles in emerging markets, none have applied the Hall, et al's (1999) Markov regime switching unit root test procedure to such markets. The major finding of the investigation is that asset prices may not result in periodically collapsing bubbles in most emerging markets. Thus, our findings provide support against the current arguments that emerging capital markets have benefited from increased liquidity rather than improved fundamentals.
\end{abstract}

Keywords: Market Bubble; Emerging Capital Markets; Regime Switching

\section{INTRODUCTION}

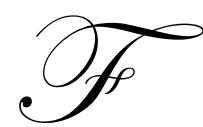

inancial markets operate in ever changing equilibria resulting in volatility. Self-adjustments occur, putting a limit on this volatility-i.e., when prices rise, more people are encouraged to sell and fewer are encouraged to buy. However, once positive feedback takes over, the market enters a state of increasing disequilibrium. This can be seen in financial bubbles where asset prices rapidly spike upwards far beyond their intrinsic value, only to fall rapidly afterwards.-i.e., the bubble has burst adding further volatility to asset prices.

The past offers several examples of bubble occurrences and their resulting collapses-i.e., the Taiwanese and Japanese bubbles at the end of the eighties, the tequila crisis (1994-95), the Asian flu and Russian virus (199798, and 1998, respectively), the dot-com bubbles at the end of the nineties, and the implosion of Argentina's economy in 2001, to name a few. Emerging capital markets are often the victims of these financial bubbles since they are evolving within weaker financial, economic and political systems translating into higher volatility of returns (Harvey, 1995a and 1995b). In fact, many papers have shown that emerging markets returns stationarity properties differ from those of developed markets, translating into a greater likelihood for the presence of asset price bubbles (Claessens, Dasgupta and Glen, 1993; Urrutia, 1995; and Karemera, Ojah, and Cole, 1999).

If behavioral biases seem to be the causes of bubbles, the phenomenon can be propagated in a rational (expectation) manner as inflated prices can be attributed to an economic paradigm shift where traditional valuation rules may no longer apply. The problem is that those buying the stocks during the bubble period were not able to identify the bubble. For instance, talking afterwards about the dot-com bubble, Greenspan argued that a stock market bubble could not be distinguished, until after it had burst, from a rise in prices of stocks due to improvements in fundamentals. Yet, history has taught us that there are some potential signs for bubbles-i.e., a build-up of shortterm indebtedness, a booming activity in the IPO market leading to issuance of new shares at inflated prices, and a soaring commodity market (specially gold) which can occur during expected financial market collapses. 
Well, commodity prices, often produced in these developing countries, have been soaring since the twentyfirst century. Recent trends toward financial globalization and its potential short-term impact on emerging markets' financial fragility (before it leads to a smother working of the financial markets), also provides grounds for bubbles. Indeed, global financial institutions are increasingly investing into the emerging markets of Latin America, Asia, Eastern Europe and Africa and the amount of borrowed Yen and Dollar invested in these markets has been in the trillions of dollars range. Professional investors' current bullishness on emerging markets is based on more prudent economic policies that developing nations have adopted, and supported by the higher ratings granted by credit agencies. For example, government bonds issued by many emerging markets (Mexico, Russia and Poland) are now investment grade. But even if most emerging-market economies are more conservatively run than they used to be, it can also be argued that the main reason for the attraction for emerging markets is the low level of interest rates in the United States, Europe and Japan, leading to huge inflows of cash and making the financial strength of many emerging markets look better than it really is. For instance, the amount of private capital flowing into emerging markets is at a all-time highs -- a total of $\$ 345$ billion in 2006, the previous record of $\$ 323$ billion was set in 1996, just before the Asian flu and the Russian virus. The money has helped to offset trade deficit and it is clear that emerging markets highly depend on these short-term investments that can flee at a moment's notice. Indeed, the recipients of these foreign investments are at the mercy of changes in macroeconomic variables leading to a weakening of the USD and Yen-i.e., if liquidity is being pulled away, stock prices will collapse.

So far, academic research has provided mixed evidence on the presence of bubbles in emerging market asset prices. For instance, Sarno and Taylor (1999) do not reject the presence of bubbles in Asian countries, Ahmed, Rosser and Uppal (1999) document the presence of bubbles in stock markets of Pacific-Rim countries, Johansen and Sornette (2001), and Lau, Tan, and Rahman (2005), point out the presence of bubbles in few Asian and Latin American countries. On the other hand, Chan, McQueen and Thorley (1998), Titman and Wei (1999), Hasan and Yu (1999) cannot confirm the presence of rational speculative bubbles in emerging stock markets.

Although there exists a consensus about the definition of bubbles, the major reason for the conflicting support for the presence of bubbles in emerging markets is methodological. The methodology used to test bubbles in emerging markets can be grouped into three types: direct tests, indirect tests and new-fangled tests. The direct tests (put forward and used by Flood and Garber, 1980; Shiller, 1981; West, 1987) are based on fundamental analysis and require complete formulation and estimation of a set of economic parameters. The indirect tests (Diba and Grossman, 1987, 1988; Hamilton and Whiteman, 1985) examines time series properties of asset prices and observable variables by estimating and observing autocorrelation patterns, unit roots, and co-integration tests. The new-fangled tests (Johansen and Sornette, 2001; Kelleher, Kim and Kim, 2001; Hassan and Yu, 2006) are based on fractional integration tests, duration analysis, Kalman filters, regime switching tests, and Brock, Dechert and Scheinkman (BDS) statistics.

The major short-coming of the direct tests used by Sarno and Taylor (1999) and Titman and Wei (2005) while investigating bubbles in emerging markets, is that they investigate only bubbles belonging to a specific parametric class. While the test may reject a bubble, it does exclude the presence of other types of bubbles. Evans (1991), Hall, Psaradakis and Sola (1999), and Hassan and Yu (2006) highlight the shortcomings of indirect tests pointing out their lack of statistical power and robustness to detect periodically collapsing bubbles. New-fangled tests, on the other hand, have the advantage to provide statistical power and are robust enough to detect regimedependent bubbles.

Our paper investigates the presence of periodically collapsing speculative bubbles in emerging markets by employing a Markov regime-switching unit root process. This approach, based on a procedure developed by Hall, Psaradakis, and Sola (1999), is a regime switching extension of the augmented Dickey Fuller test. It has the advantage to allow for changes in behavior of asset prices in the expanding and collapsing phases of a bubble. Accordingly, this framework can deal with differing dynamics in these two phases as it allows parameters can switch values between different regimes.

Using the traditional DF and ADF unit root test (indirect bubble tests), we find prices to be explosive in ten of the fourteen countries that we study. Accordingly, these results provide evidence of the propensity for emerging 
markets to develop bubbles during the period of study. The Markov regime switching unit root test, however, indicates presence of explosive regimes, and hence a bubble, in only two Asian and three Latin American emerging markets. Even if it can be argued that emerging markets fundamentals still provide grounds for bubbles, price discovery is more likely to reflect changing economic, financial and political environments than investors behavioral biases. Thus, our findings provide support against the current arguments that emerging capital markets have benefited from increased liquidity rather than improved fundamentals.

The rest of the paper is divided into three sections. Section 2 briefly discusses the Markov regime switching unit root process, section 3 discusses the results, and section 4 concludes the paper.

\section{MARKOV REGIME-SWITCHING UNIT ROOT PROCESS}

As pointed out by Evans (1991) and Hall, Psaradakis and Sola (1999) the major problem with the traditional Dickey Fuller and the Augmented Dickey Fuller unit root tests is that they do not allow for dynamics to be different in the expansionary and collapsing phases of the bubble to be different. In spite of this shortcoming the DF and ADF tests may still show presence of unit roots. Presence of unit roots may then be erroneously interpreted as evidence for the presence of bubbles, whereas the evidence merely supports non-stationarity. By incorporating the Markov regime-switching Hall, Psaradakis and Sola (1999) extend the ADF framework to overcome this major shortcoming of the traditional unit roots tests.

Consider a time series $\left\{p_{t}\right\}_{t=1}^{m}$, where $p_{t}$ represents the price level. The ADF test for this price series is represented by:

$\Delta \mathrm{p}_{\mathrm{t}}=\alpha+\beta \mathrm{p}_{\mathrm{t}-1}+\sum_{\mathrm{j}}^{\mathrm{k}} \psi_{\mathrm{j}} \Delta \mathrm{p}_{\mathrm{t}}+v_{\mathrm{t}}$

In this equation, $\Delta \mathrm{p}_{\mathrm{t}}=\mathrm{p}_{\mathrm{t}}-\mathrm{p}_{\mathrm{t}-1,}, v_{\mathrm{t}}$ is white noise and has zero mean, while $\mathrm{k}$ is a suitably chosen integer (Dickey and Fuller, 1981; Said and Dickey, 1984). The coefficient $\beta$, which is the coefficient of $\mathrm{p}_{\mathrm{t}-1}$, is used to test for unit root. By allowing parameters to be time-varying and changing with an unobserved indicator $\mathrm{s}_{\mathrm{t}} \varepsilon\{0,1\}$, Hall, Psaradakis and Sola (1999) generalize Equation 1 so that we have:

$$
\Delta \mathrm{p}_{\mathrm{t}}=\alpha_{0}\left(1-\mathrm{s}_{\mathrm{t}}\right)+\alpha_{\mathrm{t}} \mathrm{s}_{\mathrm{t}}+\left[\beta_{0}\left(1-\mathrm{s}_{\mathrm{t}}\right)+\beta_{0} \mathrm{~s}_{\mathrm{t}}\right] \mathrm{p}_{\mathrm{t}-1}+\sum_{\mathrm{j}=1}^{\mathrm{k}}\left[\psi_{0 \mathrm{j}}\left(1-\mathrm{s}_{\mathrm{t}}\right)+\psi_{0 \mathrm{j}} \mathrm{s}_{\mathrm{t}}\right] \Delta \mathrm{p}_{\mathrm{t}-1}+\sigma_{\mathrm{e}} \mathrm{e}_{\mathrm{t}}
$$

In this equation, $e_{t}$ is IID and has zero mean and unit variance. The process allows for a two state Markov process and on any particular depends on the value of the random variable $s_{t}$, which takes value of 0 or 1 based on the following probabilities: $\operatorname{Pr}\left(\mathrm{s}_{\mathrm{t}}=1 \mid \mathrm{s}_{\mathrm{t}-1}=1\right)=\mathrm{p}_{11} ; \operatorname{Pr}\left(\mathrm{s}_{\mathrm{t}}=0 \mid \mathrm{s}_{\mathrm{t}-1}=1\right)=\mathrm{p}_{10}=1-\mathrm{p}_{11} ; \operatorname{Pr}\left(\mathrm{s}_{\mathrm{t}}=0 \mid \mathrm{s}_{\mathrm{t}-1}=0\right)=\mathrm{p}_{00} ; \operatorname{Pr}\left(\mathrm{s}_{\mathrm{t}}=\right.$ $\left.1 \mid \mathrm{s}_{\mathrm{t}-1}=0\right)=\mathrm{p}_{01}=1-\mathrm{p}_{00}$

Where $\mathrm{p}_{11}$ is the probability to staying in regime $1, \mathrm{p}_{10}$ is the probability of switching from regime 1 to regime $0, p_{00}$ is the probability of staying in regime 0 , and and $p_{01}$ is the probability of switching from regime 0 to regime 1. All of the four probabilities are a function of a latent variable inherent in the estimation process of equation (2).

In equation 2, the innovations in $\mathrm{e}_{\mathrm{t}}$ are independent of $\mathrm{s}_{\mathrm{t}}$ for all $\mathrm{t}$. If suitable restrictions are applied on the stochastically chosen regimes, the Hall, Psaradakis and Sola (1999) reduces to the linear ADF framework model described in equation 1. In this paper we assume the Markov switching process to follow the ADF framework and the specific form of the process we test is:

$$
\Delta \mathrm{p}_{\mathrm{t}}=\alpha_{0}\left(1-\mathrm{s}_{\mathrm{t}}\right)+\alpha_{\mathrm{t}} \mathrm{s}_{\mathrm{t}}+\left[\beta_{0}\left(1-\mathrm{s}_{\mathrm{t}}\right)+\beta_{0} \mathrm{~s}_{\mathrm{t}}\right] \mathrm{p}_{\mathrm{t}-1}+\psi_{0 \mathrm{j}}\left(1-\mathrm{s}_{\mathrm{t}}\right)+\psi_{0 \mathrm{j}} \mathrm{st}_{\mathrm{t}} \Delta \mathrm{p}_{\mathrm{t}-1}+\sigma_{\mathrm{e}} \mathrm{e}_{\mathrm{t}}
$$


If the coefficient of $\mathrm{p}_{\mathrm{t}-1}$ is greater than zero in either regime, then a bubble is present. To compare the efficacy of the Hall, Psaradakis and Sola (1999), we also conduct the DF and ADF unit root tests.

\section{RESULTS}

The data on emerging markets is obtained from S\&P/IFC Emerging Markets Data Base (EMDB). The data consist of monthly indexes values for the seven Asian countries, and seven Latin American countries. The seven Asian countries are Bangladesh, Indonesia, Malaysia, Pakistan, Philippines, Sri Lanka, and Thailand. The countries from Latin American countries are Argentina, Brazil, Chile, Columbia, Mexico, Peru, and Venezuela. The data for most countries are for the period between January 1986 to October 2004, except Bangladesh starting from January 1996, Indonesia from January 1990, Sri Lanka, Brazil, and Peru all starting from January 1989.

Table 1: Descriptive Statistics

Summary statistics for monthly returns for the Asian an Latin countries. The symbols ** and * indicate that the null hypothesis is rejected at the $1 \%$ and $5 \%$ significance level respectively. Normality is tested using the Jarque-Bera test, which follows a chisquare distribution with two degrees of freedom.

\begin{tabular}{|c|c|c|c|c|c|}
\hline & Start Date & Observations & $\begin{array}{c}\text { Returns } \\
\text { Mean }\end{array}$ & $\begin{array}{l}\text { Standard } \\
\text { Deviation }\end{array}$ & $\begin{array}{c}\text { Test of Normality } \\
\text { Returns }\end{array}$ \\
\hline \multicolumn{6}{|l|}{ Asia } \\
\hline Bangladesh & 1996:01 & 106 & $0.59 \%$ & $13.13 \%$ & $277.60 * *$ \\
\hline Indonesia & 1990:01 & 178 & $0.46 \%$ & $13.20 \%$ & $80.480 * *$ \\
\hline Malaysia & 1986:01 & 226 & $0.70 \%$ & $9.55 \%$ & $140.02 * *$ \\
\hline Pakistan & 1986:01 & 226 & $1.03 \%$ & $9.76 \%$ & $1039.67 * *$ \\
\hline Philippines & 1986:01 & 226 & $1.43 \%$ & $10.47 \%$ & $37.63 * *$ \\
\hline Sri Lanka & 1989:01 & 166 & $0.76 \%$ & $9.19 \%$ & $11.82 * *$ \\
\hline Thailand & 1986:01 & 226 & $1.17 \%$ & $11.58 \%$ & $24.13 * *$ \\
\hline \multicolumn{6}{|c|}{ Latin America } \\
\hline Argentina & 1986:01 & 226 & $2.57 \%$ & $19.85 \%$ & $1551.56 * *$ \\
\hline Brazil & 1990:01 & 178 & $1.90 \%$ & $16.40 \%$ & $326.68 * *$ \\
\hline Chile & 1986:01 & 226 & $1.76 \%$ & $7.56 \%$ & $55.13 * *$ \\
\hline Colombia & 1986:01 & 226 & $1.88 \%$ & $8.83 \%$ & $209315.70 * *$ \\
\hline Mexico & 1986:01 & 226 & $2.24 \%$ & $11.32 \%$ & $2030.63 * *$ \\
\hline Peru & 1990:01 & 178 & $1.31 \%$ & $7.91 \%$ & $1996.75 * *$ \\
\hline Venezuela & 1986:01 & 226 & $1.31 \%$ & $13.39 \%$ & $97486.25 * *$ \\
\hline
\end{tabular}

Table 1 gives the basic summary statistics for the returns of the eleven Asian countries and seven Latin American countries. The familiar pattern of higher emerging market returns (means) and high risks (standard deviations) compared to the developed countries is evident. None of the return series for the seven Asian countries and seven Latin American countries are normally distributed with the Jarque-Bera test rejecting the normality assumption.

\subsection{Indirect Tests For Traditional Unit Roots}

Tests for the traditional unit roots - DF and ADF - test are presented in Table 2. Rather than reporting the autoregressive parameters themselves, Table 2 actually reports the test statistics for the autoregressive parameters for each of the seven countries from Asia and seven countries from Latin America. Given the sample size of this study, the critical value under 5\% and $1 \%$ confidence level is -2.8418 and -3.4455 respectively. Both the DF test and the ADF test come with the null hypothesis that the series exhibits a unit root. If the test statistics reported are greater than the critical value, the null hypothesis then cannot be rejected and non-stationarity will be concluded. If the test statistics reported are lower than the critical value, we can then reject the null of unit root and do not reject stationarity. Observing Table 1, using DF method, out of the seven Asian countries, only two countries, Malaysia and Thailand, can reject the null hypothesis of non-stationary and reject the existence of unit root. Using ADF 
method, out of the seven Asian countries, three of them, Indonesia, Malaysia, and Thailand, could reject the null hypothesis of non-stationary and unit root. The test statistics for the rest six countries are greater than the critical value and therefore we cannot reject the null that each index series exhibit a unit root. Hence those series are not stationary.

Out of the seven Latin American countries, only Chile can reject the null hypothesis of non-stationarity and unit root under DF method, though not under ADF method. The rest six countries, including Argentina, Brazil, Colombia, Mexico, Peru, and Venezuela, show test statistics greater than the critical value. Therefore, we cannot reject the null that each index series of the above 6 countries exhibits a unit root.

\section{Table 2: Traditional DF and ADF Unit Root Test}

This table presents the results from the traditional unit root test, Dickey-Fuller test and Augmented Dickey-Fuller test, for the overall sample period.

The Dickey-Fuller unit root test takes the following format: $\Delta \mathrm{p}_{\mathrm{t}}=\alpha_{0}+\beta_{0} \mathrm{p}_{\mathrm{t}-1}+\varepsilon_{\mathrm{t}}$

The Augmented Dickey-Fuller unit root test takes the following format: $\Delta \mathrm{p}_{\mathrm{t}}=\alpha_{0}+\beta_{0} \mathrm{p}_{\mathrm{t}-1}+\psi \Delta \mathrm{p}_{\mathrm{t}-1}+\varepsilon_{\mathrm{t}}$

The null hypothesis for the DF and ADF tests is that each series exhibits a unit root and is nonstationary. $* *$ and $*$ indicate significance at the $1 \%$ and $5 \%$ level respectively.

\begin{tabular}{ccc}
\hline Countries & DF test: test statistics & ADF test: test statistics \\
\hline \hline Panel A: Asia & & -1.6344 \\
Bangladesh & -0.9549 & $-3.8768^{* *}$ \\
Indonesia & -2.5961 & $-3.4781^{* *}$ \\
Malaysia & $-2.9410^{*}$ & -2.4613 \\
Pakistan & -2.1868 & -1.8038 \\
Philippines & -1.0577 & -1.5756 \\
Sri Lanka & -1.1702 & $-4.1800^{* *}$ \\
Thailand & $-3.4342^{*}$ & -1.8126 \\
\hline Panel B: Latin America & & -2.7761 \\
Argentina & -1.7688 & -2.3205 \\
Brazil & -1.7465 & -2.3358 \\
Chile & $-3.2209 *$ & -2.6794 \\
Colombia & -2.1097 & -2.0378 \\
Mexico & -2.2964 & -1.4531 \\
Peru & -2.6211 & -1.1715 \\
Venezuela &
\end{tabular}

Non-stationarity in price levels is necessary, but not a sufficient condition to conclude with certainty on the presence of bubbles. Indeed, The DF and ADF tests does not necessarily indicate that an explosive bubble is present in the fourteen countries under investigation. They only indicate that the markets might potentially include bubbles. Thus, we need to refine our analysis by accounting for transitional regimes of volatility to detect the presence of bubbles in these emerging markets.

\subsection{Test For Markov Switching Unit Roots Under ADF Framework}

As discussed before, the traditional unit root test, including DF and ADF tests reported in the previous section have been criticized as not being robust enough to detect periodically collapsing bubbles. Hence, our study applies a Markov switching unit root test similar to that developed by Hall, Psaradakis and Sola (1999). Results of the Markov switching unit roots based on ADF framework for the sample periods for each of the seven Asian countries and seven Latin America countries are tabulated in Table 3. This Markov switching unit root model allows the intercept, the autoregressive parameter, and the error variance to be regime dependent; hence it is better able to test the underlying economic structure of the time series. The time series can switch between two regimes, one of which could be stationary and another non-stationary, or both non-stationary, or both stationary but with different adjusting speeds. Table 3 reports the intercept $\left(\alpha_{0}\right.$ and $\left.\alpha_{1}\right)$, the autoregressive parameter $\left(\mathrm{AR}_{0}\right.$ and $\left.\mathrm{AR}_{1}\right)$, 
the parameter for lagged variable $\left(\psi_{0}\right.$ and $\left.\psi_{1}\right)$, the error variance $\left(\operatorname{Var}_{0}\right.$ and $\left.\operatorname{Var}_{1}\right)$, and the probability of staying in each regime $\left(\mathrm{P}_{00}\right.$ and $\left.\mathrm{P}_{11}\right)$ under the two regimes. The autoregressive parameter, $\mathrm{AR}_{0}$ and $\mathrm{AR}_{1}$, are of particular interest to this study. If it is significantly lower than zero, we can conclude that the time series is in a stationary regime. If the autoregressive parameter is significantly greater than zero, we can conclude the existence of an explosive bubble. Otherwise, if the autoregressive parameter is just not significantly different from zero, we can only conclude the existence of a unit root, rather than a bubble.

Table 3: Regime Switching Markov Unit Tests under ADF Framework

This table shows the results of the regime switching markov unit root test for the overall period. The ADF Markov switching unit root model is defined as follows.

$$
\left.\Delta \mathrm{p}_{\mathrm{t}}=\alpha_{0}\left(1-\mathrm{s}_{\mathrm{t}}\right)+\alpha_{0} \mathrm{~s}_{\mathrm{t}}+\mid \beta_{0}\left(1-\mathrm{s}_{\mathrm{t}}\right)+\beta_{0} \mathrm{~s}_{\mathrm{t}}\right\rfloor \mathrm{p}_{\mathrm{t}-1}+\psi_{0}\left(1-\mathrm{s}_{\mathrm{t}}\right)+\psi_{0} \mathrm{~s}_{\mathrm{t}} \Delta \mathrm{p}_{\mathrm{t}-1}+\sigma_{\mathrm{e}} \varepsilon_{\mathrm{t}}
$$

$\mathrm{AR}_{0}$ and $\mathrm{AR}_{1}$ are the autoregressive coefficients $(\beta)$ in state 0 and state 1 . A coefficient significantly less than zero (one-tail test applied) indicates a stationary regime, while a coefficient larger than zero indicates explosive behavior. A bubble exists when $\mathrm{AR}_{0}$ or $\mathrm{AR}_{1}>0 . * *$ and $*$ indicate significance at the $1 \%$ and $5 \%$ level respectively.

\begin{tabular}{|c|c|c|c|c|c|c|c|c|c|c|}
\hline \multicolumn{11}{|c|}{ Panel A: Asia } \\
\hline Countries & $\alpha_{0}$ & $\alpha_{1}$ & $\mathrm{AR}_{0}$ & $\mathrm{AR}_{1}$ & $\psi_{0}$ & $\psi_{1}$ & $\mathrm{P}_{00}$ & $\mathrm{P}_{11}$ & $\operatorname{Var}_{0}$ & Var $_{1}$ \\
\hline \multirow[t]{2}{*}{ Bangladesh } & -0.004 & -0.201 & 0.0008 & $0.0379 * *$ & -0.0490 & -0.3774 & 0.7051 & 0.5238 & $0.0001 * *$ & $0.0001 * *$ \\
\hline & 0.002 & 0.001 & 0.0004 & 0.0001 & 0.1833 & 0.2601 & & & 0.0000 & 0.0000 \\
\hline \multirow[t]{2}{*}{ Indonesia } & -0.173 & -0.059 & $-0.2 * *$ & 0.0449 & $6.525 * *$ & -0.0059 & 0.6257 & 0.7208 & $0.0011 * *$ & $0.2025 * *$ \\
\hline & 0.0024 & 0.140 & 0.001 & 0.1031 & 0.0161 & 0.0098 & & & 0.0002 & 0.0168 \\
\hline \multirow[t]{2}{*}{ Malaysia } & 0.0023 & 0.021 & -0.021 & 0.0802 & 0.0233 & 0.0705 & 0.7285 & 0.7259 & $0.0331 * *$ & $0.0807 * *$ \\
\hline & 0.0037 & 0.017 & 0.0332 & 0.0492 & 0.1230 & 0.1693 & & & 0.0049 & 0.0216 \\
\hline \multirow[t]{2}{*}{ Pakistan } & -0.004 & -0.013 & 0.0037 & 0.0041 & 0.0800 & 0.1545 & 0.7245 & 0.7138 & $0.0244 * *$ & $0.0678 * *$ \\
\hline & 0.0351 & 0.1939 & 0.0147 & 0.0848 & 0.3990 & 0.5658 & & & 0.0022 & 0.0082 \\
\hline \multirow[t]{2}{*}{ Philippines } & -0.007 & -0.193 & 0.0075 & $0.1615^{* *}$ & 0.0003 & $2.9229 * *$ & 0.7217 & 0.5885 & $0.0775^{* *}$ & $0.0031 * *$ \\
\hline & 0.0118 & 0.0069 & 0.0105 & 0.0051 & 0.6273 & 0.0450 & & & 0.0094 & 0.0010 \\
\hline \multirow[t]{2}{*}{ Sri Lanka } & -0.010 & -0.087 & 0.0066 & 0.0483 & 0.0132 & 0.6337 & 0.6850 & 0.5473 & $0.0338 * *$ & $0.0688 * *$ \\
\hline & 0.0241 & 0.0764 & 0.0140 & 0.0442 & 0.0918 & 0.5731 & & & 0.0036 & 0.0028 \\
\hline \multirow[t]{2}{*}{ Thailand } & 0.0350 & -0.004 & -0.009 & 0.0022 & 0.1017 & 0.0612 & 0.7148 & 0.7256 & $0.0925^{* *}$ & $0.0375 * *$ \\
\hline & 0.0936 & 0.0322 & 0.0142 & 0.0419 & 0.1523 & 0.1128 & & & 0.0082 & 0.0040 \\
\hline \multicolumn{11}{|c|}{ Panel B: Latin America } \\
\hline Countries & $\alpha_{0}$ & $\alpha_{1}$ & $\mathrm{AR}_{0}$ & $\mathrm{AR}_{1}$ & $\psi_{0}$ & $\psi_{1}$ & $\mathrm{P}_{00}$ & $\mathrm{P}_{11}$ & $\operatorname{Var}_{0}$ & Var $_{1}$ \\
\hline \multirow[t]{2}{*}{ Argentina } & 0.0187 & -2.26 & 0.0004 & $0.7085^{* *}$ & $-0.987 * *$ & -0.6878 & 0.7149 & 0.5223 & $0.0808 * *$ & $0.5780^{* *}$ \\
\hline & 0.0552 & 0.6426 & 0.0168 & 0.2089 & 0.0091 & 0.1458 & & & 0.0054 & 0.0814 \\
\hline \multirow[t]{2}{*}{ Brazil } & 0.062 & -0.060 & -0.0132 & 0.0157 & 0.0093 & -0.1058 & 0.6815 & 0.6625 & $0.0364 * *$ & $0.1002 *$ \\
\hline & 0.213 & 0.296 & 0.0642 & 0.0841 & 0.3873 & 0.3125 & & & 0.0402 & 0.0564 \\
\hline \multirow[t]{2}{*}{ Chile } & -0.061 & -1.240 & $0.0642 * *$ & $1.2065^{* *}$ & $-0.961 * *$ & -0.2771 & 0.7255 & 0.5499 & $0.0825^{* *}$ & $0.7521 * *$ \\
\hline & 0.025 & 0.4246 & 0.0214 & 0.3898 & 0.0109 & 0.2892 & & & 0.0059 & 0.0528 \\
\hline \multirow[t]{2}{*}{ Colombia } & -0.011 & $-2.6 * *$ & 0.0072 & $1.5680 * *$ & $0.2109 * *$ & -0.5224 & 0.7277 & 0.6584 & $0.0324 * *$ & $0.4079 * *$ \\
\hline & 0.0157 & 0.731 & 0.0078 & 0.3533 & 0.0749 & 0.3795 & & & 0.0018 & 0.1049 \\
\hline \multirow[t]{2}{*}{ Mexico } & 0.0176 & 0.0503 & -0.0307 & -0.0152 & 0.3445 & 0.0766 & 0.6706 & 0.7261 & $0.1591 * *$ & $0.0378 * *$ \\
\hline & 0.5081 & 0.0263 & 0.1972 & 0.0099 & 0.4611 & 0.0727 & & & 0.0315 & 0.0026 \\
\hline \multirow[t]{2}{*}{ Peru } & 0.1217 & -0.080 & -0.0368 & 0.0307 & -0.2022 & $0.1885 * *$ & 0.6994 & 0.7198 & $0.1049 * *$ & $0.0272 * *$ \\
\hline & 0.0918 & 0.047 & 0.0364 & 0.0175 & 0.1906 & 0.0873 & & & 0.0248 & 0.0026 \\
\hline \multirow[t]{2}{*}{ Venezuela } & 0.0034 & -0.784 & 0.0009 & 0.3206 & 0.0038 & 4.0496 & 0.5000 & 0.7243 & $0.0531 * *$ & $0.5368 * *$ \\
\hline & 0.0095 & 0.186 & 0.0058 & 0.1952 & 0.0313 & 2.7110 & & & 0.0035 & 0.0441 \\
\hline
\end{tabular}

As has been reported in Table 3, out of the seven Asian countries, only two countries, Bangladesh and Philippines, report two regimes with one regime being non-stationary but no bubble and the other with an explosive bubble, since one regime has an autoregressive parameter not significantly from zero, while the other regime has an autoregressive parameter significantly greater than zero. Indonesia features one stationary regime and the other regime nonstationary though not a bubble, since one regime features a autoregressive parameter significantly lower than zero, while the other regime's is not significant different from zero. The remaining five countries, including 
Malaysia, Pakistan, Sri Lanka, Thailand, show the existence of two regimes with similar nonstationary features since both autoregressive parameters are not significantly from zero, though each regime has different intercepts and different error variances.

Out of the seven Latin American countries, Argentina, Chile and Colombia feature one regime being nonstationary but no bubble and the other regime with an explosive bubble. Brazil, Mexico, Peru, and Venezuela show the existence of two regimes with similar nonstationary feature though not bubble-like.

The transition probability $\left(\mathrm{P}_{00}\right.$ and $\left.\mathrm{P}_{11}\right)$ refer to the transition probability that the series will remain in state 0 or remain in state 1 . The results indicate that nearly all of the countries have a very high probability (more than $50 \%$ ) of staying in their original state while the transition probability of moving from one state to another is not quite as large (less than $50 \%$ ).

\section{CONCLUSION}

Studying the time series properties of emerging markets has been of continued interested in the finance literature. The asset prices in emerging markets exhibit properties which may indicate presence of bubbles. However, the existing empirical evidence is mixed. For example, Sarno and Taylor (1999), Titman and Wei (1999), Ahmed, Rosser and Uppal (1999), Johansen and Sornette (2001), and Lau, Tan, and Rahman (2005) find some evidence for the presence of bubbles. Chan, McQueen and Thorley (1998), and Hasan and Yu (1999), however, do not find strong support for the presence of bubbles in emerging markets.

This article contributes by applying the Markov regime switching unit root process developed by Hall, Psaradakis, and Sola (1999) to test the presence of periodically collapsing bubbles in the Asian and Latin American emerging markets. The advantage of this test that it is robust enough to allow for the expansive and collapsing phases of a bubbles, something which the traditional unit root tests like the Dickey-Fuller and Augmented DickeyFuller tests are unable to accommodate. The presence of unit roots in the he traditional unit root tests may erroneously interpreted as the bubble, whereas it may only be indicating the time series to be non-stationary. The Markov regime switching tests may exhibit non-stationarity without a bubble if it so was the case. Our results basically indicate that only the time series of asset prices in emerging markets exhibit conditions for the presence of bubbles, periodically collapsing bubbles are found to exist in only a few such countries.

\section{REFERENCES}

1 Ahmed, E., J. Barkley Rosser, Jr., and Jamshed Y. Uppal, 1999, Evidence of Nonlinear Speculative Bubbles in Pacific-Rim Stock Markets, The Quarterly Review of Economics and Finance, vol. 39., pp 2136

2. Barberis, N., Shleifer, A. and R. Vishny, 1998, A Model of Investor Sentiment, Journal of Financial Economics, vol. 49, pp. 307-343.

3. Blanchard, O. J., and M. W. Watson, 1982, Bubbles, Rational Expectations and Financial Markets. In Crises in the Economic and Financial Structure, P. Wachtel (ed.), Lexington Books, pp 295-315

4. Boudoukh, Jacob, Matthew Richardson and Robert Whitelaw, 1994, Industry Returns and the Fisher Effects, Journal of Finance, vol. 49, pp. 1595-1615.

5. Chan, Kolak, Grant McQueen, and Steven Thorley, 1998, Are there rational speculative bubbles in Asian stock markets?, Pacific-Basin Finance Journal, vol. 6. pp 125-151

6. Claessens, S., S. Dasgupta and J. Glen, 1993, Stock price behavior in Emerging stock markets, World Bank Working paper

7. Conrad, J. and G. Kaul, 1998, An Anatomy of Trading Strategies, Review of Financial Studies, vol. 11, pp. 489-519.

8. Daniel, K.D., Hirshleifer, D. and A. Subrahmanyam, 1998, Investor Psychology and Security Market Under-and Over-Reactions, Journal of Finance, vol. 53, pp. 1839-1885.

9. Diba, Behzad T. and Herchel I. Grossman, 1987, On the Inception of Rational Bubbles, Quarterly Journal of Economics, vol. 102, pp. 697-700.

10. Diba, Behzad T. and Herchel I. Grossman, 1988; Rational Inflationary Bubbles, Journal of Monetary Economics, vol. 21, pp. 35-46. 
11. Dickey, D. A. and W. A. Fuller, 1981, Likelihood Ratio Statistics for Autoregressive Time Series with a Unit Root, Econometrica, vol. 49, pp. 1057-1072.

12. Evans, G. W., 1991, Pitfalls in Testing for Explosive Bubbles in Asset Prices, American Economic Review, vol. 81 (No. 2 , September), pp. 922-930.

13. Flood, Robert P. and Peter M. Graber, 1980, Market Fundamentals and Price Level Bubbles: The First Tests, Journal of Political Economy, vol. 88, pp. 745-770.

14. Flood, Robert P., Peter M. Graber and L.O. Scott, 1984, Multi-currency Tests for Price Level Bubbles, Journal of Economic Dynamics and Control, vol. 8, pp. 329-340.

15. Harvey, C. (1995a). The Cross-Section of Volatility and Autocorrelation in Emerging Markets. Finanzmarkt und Portfolio Management 9, 12-34.

16. Harvey, C. (1995b). The Risk Exposure of Emerging Equity Markets. World Bank Economic Review, 19-50.

17. Hall, Stephen G., Psaradakis Zacharias and Martin Sola, 1999, Detecting Periodically Collapsing Bubbles: A Markov-switching Unit Root Test, Journal of Applied Econometrics, vol. 14 (No. 2, Mar/Apr 1999), pp.143-154.

18. Hamilton, James D, 1989, A New Approach to the Economic Analysis of Nonstationary Time Series and the Business Cycle, Econometrica, vol. 57 (No. 2, March), pp. 357-384.

19. Hamilton, James D. and Charles Whiteman, 1985, The Observable Implications of Self-Fulfilling Speculative Price Bubbles, Journal of Monetary Economics, vol. 16 (November), pp. 353-373.

20. Hassan, M. K., and Jung-Suk Yu, (2006), Rational speculative bubbles in the frontier emerging stock markets, Under review at Journal of Empirical Finance

21. Johansen, Anders, and Didier Sornette, 2001, Bubbles and Anti-bubbles in Latin-America, Asian, and Western Stock Marekts: An Empirical Study, International Journal of Theoretical and Applied Finance, vol. 4, pp 853-920

22. Jorion, Phillipe, 1991, The Pricing of Exchange Rate Risk in the Stock Markets, Journal of Financial and Quantitative Analysis, vol. 26, pp. 363-379.

23. Karemera, David, Kalu Ojah, and John A. Cole, 1999, Random Walks and Market Efficiency tests: Evidence from Emerging Markets, Review of Quantitative Finance and Accounting, vol. 13, pp 171-188

24. Kelleher, David, Kim, Geum-Soo and Kim, Suduk, 2001, Evidence of Bubbles in the Korean Stock Markets, EFMA 2001 Lugano Meetings. Available at SSRN: http://ssrn.com/abstract=268922

25. Kindelberger, Charles, P. 1996, Manias, Panics and Crashes: A History of Financial Crisis, Edition 3, John Wiley and Sons Inc.

26. Lau, Ee Leng, G.K. Randolph Tan, and Shahidur Rahman, 2005, Assessing pre-crisis fundamentals in selected Asian Stock Markets, The Singapore Economic Review, vol. 50. pp 175-196

27. Minsky, Hyman P., 1975, John Maynard Keynes (New York: Columbia University Press, 1975), and idem, The Financial Instability Hypothesis: Capitalistic Processes and the Behavior of the Economy, in C.P. Kindelberger and J.P. Laffargue, eds., Financial Crises: Theory, History and Policy (Cambridge: Cambridge University Press, 1982), pp. 13-29.

28. Moskowitz, Tobias and Mark Grinblatt, 1999, Do Industries Explain Momentum? Journal of Finance, vol. 54 (No. 4), pp. 1249-1290.

29. Pan, Ming-Shiun, Liano, Kartono and Gow-Cheng Huang, 2004, Industry Momentum Strategies and Autocorrelations in Stock Returns, Journal of Empirical Finance vol. 11, pp. 185-202.

30. Said, S. E. and D.A. Dickey, 1984, Testing for Unit Roots in Autoregressive-moving Average Models of Unknown Order, vol. 7, pp. 599-607.

31. Sarno, Lucio, and Mark P. Taylor, 1999, Moral hazard, asset price bubbles, capital flows and the East Asian crisis: the first test, Journal of International Money and Finance, vol. 18, pp 637-657

32. Shiller, Robert J., 1981, Do Stock Prices Move Too Much to be Justified by Subsequent Changes in Dividends? The American Economic Review, vol. 171, no. 3, pp. 421-436.

33. Titman, Sheridan, and K.C. John Wei, 1999, Understanding stock market volatility: The case of Korea and Taiwan, vol. 7, pp 41-66

34. Urrutia, J.L., 1995, Tests of random walk and market efficiency for Latin American equity markets, The Journal of Financial Research, vol. 18, pp 299-309

35. West, Kenneth D., 1987, A Specification Test for Speculative Bubbles, Quarterly Journal of Economics, vol. 102, pp. 553-580. 